\title{
Reproductive performance of Propylea japonica (Coleoptera: Coccinellidae) under various light intensities, wavelengths and photoperiods
}

\author{
Su WANG ${ }^{1}, \mathrm{KUN}_{\mathrm{WANG}}{ }^{1,2}$, J.P. MICHAUD ${ }^{3 *}$, FAN ZHANG $^{1}$ and XIAO-LING TAN ${ }^{1}$ \\ ${ }^{1}$ Institute of Plant and Environment Protection, Beijing Academy of Agriculture and Forestry Sciences, Beijing, China \\ ${ }^{2}$ College of Plant Protection, China Agriculture University, Beijing, China \\ ${ }^{3}$ Department of Entomology, Agricultural Research Center-Hays, 1232 240th Ave., Hays, Kansas, 67601, USA; \\ e-mail:.jpmi@ksu.edu
}

Key words. Coleoptera, Coccinellidae, Propylea japonica, copulation, fecundity, fertility, light intensity, wavelength, photoperiod

\begin{abstract}
Cocccinellid beetles are largely diurnal species that are known to utilize visual cues in foraging and reproduction and to respond in specific ways to various light conditions. The present study evaluated the mating behavior and reproductive performance of Propylea japonica (Thunberg), a species indigenous to Asia, under various conditions of light intensity, photoperiod, and wavelength. Video-recording was used to continuously observe mating pairs for $24 \mathrm{~h}$ and a night vision system was employed to record nocturnal activity. Subsequently, males were removed and eggs were collected from females for 10 days and held under the same photic conditions to determine their fertility. The frequency and duration of copula varied among photic regimes in all experiments and tended to be negatively correlated, but more copulations occurred in photophase than in scotophase. White light at 1500 lux yielded higher egg production when compared to other light intensities, but egg fertility was higher at lower light intensities and highest in complete darkness, a result inferred to reflect egg sensitivity to light. Both fecundity and fertility were greater when 1500 lux white light was provided in a $16 \mathrm{~L}: 8 \mathrm{D}$ photoperiod compared to shorter days. Green light yielded the highest net fertility compared to other wavelengths. A scheme is proposed to optimize photic conditions for reproductive adults of $P$. japonica and their eggs in colonies mass-reared for biological control applications.
\end{abstract}

\section{INTRODUCTION}

The various properties of light, its wavelength, intensity and periodicity (daylength) can all have wide-ranging impacts on insect physiology and behavior. Daylength is a reliable indicator of seasonal change and is therefore the primary trigger of diapause induction in many temperate climate species (Beck, 1974; Denlinger, 2002). Foraging and reproductive behaviors may also be modulated in subtle ways by responses to daylength. For example, photoperiod interacts with temperature and host plant to influence the predation rate of Macrolophus pygmaeus Rambur (Hemiptera: Miridae) (Perdikis et al., 2004). Rasekh et al. (2010) demonstrated that adult females of the parasitoid Lysiphlebus fabarum (Marshall) foraging for aphids increase their patch residence time when they develop under short days within their host. Selective responses to light of different wavelengths, either transmitted or reflected, are also well-documented in insects (e.g., Langevelde et al., 2011). For example, the attractiveness of yellow to aphids (and their natural enemies) is likely a function of this color being indicative of either young or senescent plant tissues, either of which can be nutritious food sources (Kennedy et al., 1961). Similarly, green is often attractive to plant-feeding insects and the species that attack them, as it is usually associated with plants (Goff \& Nault, 1984). In contrast, visible wavelengths of light at extremes of the visual range are generally less attractive to predatory insects (Abenes \&
Khan, 1990). For pest insects attracted to UV and blacklight traps, less attractive visible wavelengths have been proposed for use as deterrant stimuli in "push-pull" management strategies (Pawson et al., 2009).

Aphidophagous coccinellids are primarily diurnal insects that utilize visual cues to guide many of their essential activities. For example, visual prey recognition by Coccinella septempunctata L. occurs at a distance of ca. $7 \mathrm{~mm}$, which corresponds to the fixed focal distance of its compound eye (Nakamuta, 1984). Coccinellids also exhibit sensitivity to light conditions such as wavelength (Veeresh, 1974; Nalepa, 2013) and photoperiod (e.g., Wang et al., 2013b). Coccinellids have color vision and, when foraging, species vary considerably in how they respond to both prey color and its contrast with background coloration (Harmon et al., 1998). Until recently, however, little attention has been given to how lighting conditions or wavelength may influence their mating behavior and reproductive performance. Omkar et al. (2005) examined the development and reproduction of Cheilomenes sexmaculata (F.) and Propylea dissecta (Mulsant) and found that red and blue light generally delayed immature development and reduced aphid consumption, oviposition, and egg viability in comparison with white light. Similarly, Omkar \& Pathak (2006) found that white light was superior to any monochromatic light for the developoment and reproduction of Coelophora saucia (Mulsant).

\footnotetext{
* Corresponding author.
} 
Propylea japonica is a beneficial species native to Asia and important in biological control of aphids, whiteflies, thrips, spider mites and the eggs of some Lepidoptera (Ouyang et al., 2012; Wang et al., 2013c). It is widely released in greenhouse cultures because of its tolerance of high temperature, low humidity conditions (Kawauchi, 1983) and the suitability of various whitefly and aphid species for its development and reproduction (Chi \& Yang, 2003; Zhang et al., 2007). Techniques for mass rearing $P$. japonica on artificial diet have been developed (Tan et al., 2014) and although suitable thermal conditions are well defined, the ideal light conditions and regimes for mating behavior, oviposition rate, and egg fertility have not yet been explored and were therefore the focus of this study. To this end, we employed LED illuminators under temperature-controlled conditions to manipulate light photoperiod, wavelength and intensity and continuously monitored $P$. japonica mating behavior under both light and dark conditions using digital video recording equipment and an infrared, night-vision camera (Noldus et al., 2002). The reproductive success of females (egg production and egg fertility) was subsequently monitored under the same light conditions and the data were used to construct a scheme for optimizing photic conditions for reproducing $P$. japonica in laboratory colonies mass-reared for biological control purposes.

\section{MATERIAL AND METHODS}

\section{Insects}

Twenty pairs of $P$. japonica adults, of the most common phenotype "ancora" (Pan et al., 2010) were collected from a maize field at the Beijing Academy of Agriculture and Forestry Sciences (BAAFS) in July, 2013. The beetles were confined in a plastic frame cage $(45.0 \times 45.0 \times 50.0 \mathrm{~cm})$ covered with mesh fabric and provisioned daily with 100 microcapsules of an artificial diet previously demonstrated to be suitable food for successful development and reproduction in this species (Tan et al., 2014). Several young seedlings of broad bean, Vicia faba (5 leaf stage) were also placed in the cage and refreshed every two days. Egg clusters were removed daily and placed in a different cage until eclosion. Hatching larvae (80-100 larvae per cage) were reared on an ad libitum diet of microcapsules refreshed daily until pupation, along with bean seedlings refreshed every two days. Newly emerged adults were sexed and then confined in same sex groups in ventilated plastic boxes $(20.0 \times 15.0 \times 30.0 \mathrm{~cm}), 15$ adults per box. The rearing conditions were controlled by an automated environment management system (WSK-2000, Vista-Huibang, Beijing, China) set to $25.0 \pm 1.0^{\circ} \mathrm{C}, 65 \% \mathrm{RH}$, and 1500 lux white light with photoperiod $12 \mathrm{~L}: 12 \mathrm{D}$.

\section{Video recording}

An automated, behavior-tracking system (CASO-L, Camsonar, London, UK) was used to continuously monitor mating and oviposition behavior under various light conditions, including low light intensities and complete darkness. A controlled environment growth chamber was fitted with a light sensor, a behavior tracking/monitoring camera, an infrared camera, and multiband LED illuminators. The behavior-tracking camera was mounted above the observation arena (Fig. 1) and focused on the center of the arena, monitoring a circle $40.0 \mathrm{~cm}$ in diameter. The surface of the arena was covered with a circular piece of black construction paper $(45.0 \mathrm{~cm}$ diam) to provide a dark background for observa-

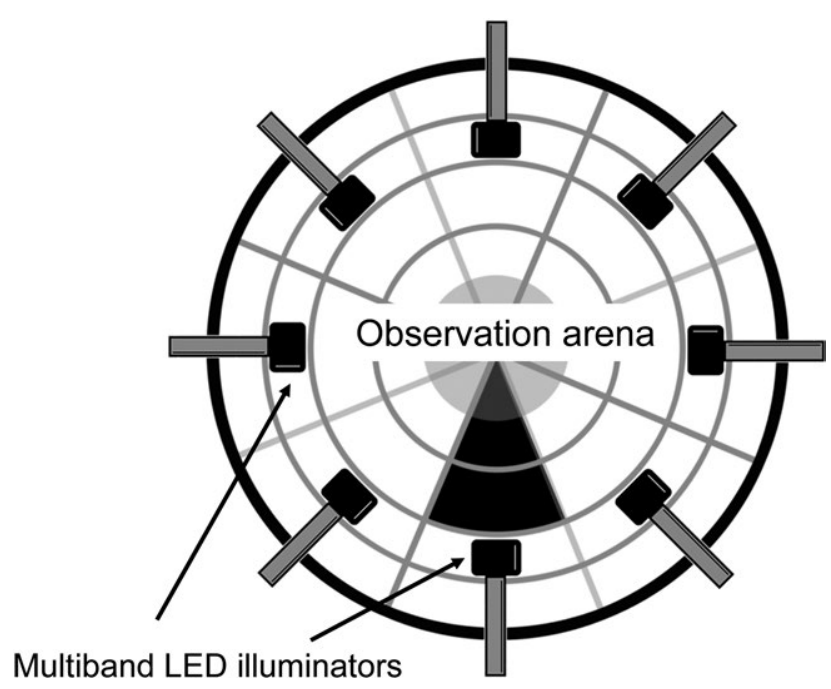

Fig. 1. Diagram of observation arena showing orientation of light sources.

tions. This paper was replaced after every set of observations. During observations, the arena was rotated on a turntable at a speed of $1.5 \mathrm{rpm}$ for a $1.0 \mathrm{~h}$ warm-up period before insects were introduced and behavioral recording initiated. Physical conditions during experiments were the same as the stock culture except as otherwise specified.

\section{Mating and reproductive performance assay}

In each experiment, individual pairs of 10-d-old virgin $P$. japonica ( $\mathrm{n}=20$ per treatment, per experiment) were brought together in the arena, provisioned with 50 diet microcapsules, and covered with a transparent glass dish $(50.0 \mathrm{~cm}$ diam $\times 3.0 \mathrm{~cm}$ height). Except for the trial in complete darkness, all insects were introduced to the arena at the beginning of photophase. The mating behavior of each insect pair was continuously observed for $24 \mathrm{~h}$ under the specified lighting conditions, whereupon the male was removed and the female maintained under the same lighting treatment for the next 10 days, with several excised bean leaves provided daily as an oviposition substrate. All eggs were removed daily to another plastic petri dish $(9.0 \mathrm{~cm})$ and placed in a growth chamber (MH-351, SANYO, Japan) under the same conditions as the behavioral arena. We recorded the 10-day fecundity of each female, and the proportion of eggs hatching, under the same lighting conditions.

\section{Lighting treatments}

Four separate experiments were performed that tested for effects of continuous light dark conditions, light intensity, photoperiod, and wavelength, respectively. In the first experiment, all illuminators were turned off and the infrared camera activated for the dark treatment, whereas 1500 lux of white light was provided continuously in the light treatment. In the second experiment, insects were held under a $12 \mathrm{~L}: 12 \mathrm{D}$ photoperiod and subjected to six light intensities: 600, 900, 1200, 1500, 1800 and 2100 lux. In the third experiment, mating pairs experienced one of three different photoperiods, $\mathrm{L}: \mathrm{D}=6: 18,12: 12$, and $18: 6$, in each case using white light at 1500 lux. In the fourth, we observed reproductive performance under six different wavelengths of light $=$ $395 \mathrm{~nm}$ (violet), $480 \mathrm{~nm}$ (blue), $510 \mathrm{~nm}$ (green), $575 \mathrm{~nm}$ (yellow), $610 \mathrm{~nm}$ (orange) and $685 \mathrm{~nm}$ (red), each produced at an intensity of 1500 lux by multiband LED illuminators and supplied in a 12L: 12D photoperiod. 
TABLE 1. Mean $( \pm$ SE) duration of various components of mating behavior when 10 d-old virgin Propylea japonica adults $(n=20$ per treatment) were paired in an experimental arena for $24 \mathrm{~h}$ in either complete darkness or continuous white light (1500 lux).

\begin{tabular}{ccccc}
\hline Light conditions & Latent period $(\mathrm{min})$ & Pursuit time $(\mathrm{s})$ & No. copulations & Duration of copula (min) \\
\hline Light & $313.4 \pm 6.3$ & $5.3 \pm 0.14$ & $5.4 \pm 0.17$ & $92.4 \pm 2.1$ \\
Dark & $262.7 \pm 5.5$ & $1.6 \pm 0.05$ & $2.9 \pm 0.17$ & $156.8 \pm 3.7$ \\
$F$ & 36.8 & 618.1 & 115.74 & 232.7 \\
df & 1,38 & 1,38 & 1,38 & 1,38 \\
$P$ & $<0.001$ & $<0.001$ & $<0.001$ & $<0.001$ \\
\hline
\end{tabular}

\section{Observations of mating behavior}

Video analysis software (Camsonar Image MP-1.1, CIMP-1.1) was used to analyze the behavior tracking video. Two discrete behavioral activities were discernable: (1) pursuit - beginning with arrestment of male movement following initial contact with female, subsequent male following, and ending with successful mounting of the female and; (2) copulation - tallied as the period during which the male remained on top of the female. In addition, the initial latent period (LP) was tallied as the time from introduction of the insects into the arena until initiation of the first pursuit.

\section{Analysis}

All data passed a Shapiro-Wilk test for normality and a Levene test for equality of variances and were then subjected to a one-way ANOVA. Treatment means were separated by Fisher's LSD test $(\alpha=0.05)$ in cases where three or more treatments were compared.

\section{RESULTS}

\section{Light vs dark}

When mating in darkness, the initial latent period prior to copula was reduced, but males also reduced the time spent in pursuit and in copula, and fewer copulations were obtained relative to fully lighted conditions (Table 1). The 10day fecundity of females did not differ between light and dark conditions (mean $\pm \mathrm{SE}=151.7 \pm 2.7$ vs $143.9 \pm 3.0$, $\left.\mathrm{F}_{(1,38)}=3.88, \mathrm{P}=0.056\right)$, but a significantly lower percentage of eggs hatched in continuous light than in continuous dark (mean $\pm \mathrm{SE}=63.0 \pm 2.5 \%$ vs $85.2 \pm 2.1 \%, \mathrm{~F}_{(1,38)}=46.2$, $\mathrm{P}<0.001)$.

\section{Light intensity}

Initial latent periods and male pursuit times varied with light intensity, but in no consistent manner (Table 2). The duration of copula was highest at 900 lux and diminished as light intensity increased to 1200 lux and beyond. The opposite trend was observed for number of copulations which increased with light intensity. The 10-day fecundity of females was highest at 1500 lux and declined at both lower and higher light intensities $\left(\mathrm{F}_{(5,114)}=7.3, \mathrm{P}<0.001\right.$, Fig. 2A). In contrast, egg viability was progressively diminished at light intensities of 1200 lux and above $\left(\mathrm{F}_{(5,114)}\right.$ $=3.0, \mathrm{P}<0.001$, Fig. 2B).

\section{Photoperiod}

Durations of copula decreased with increasing photoperiod, but periods of male pursuit increased (Table 3). Female 10-d fecundity increased with length of photoperiod $\left(\mathrm{F}_{(2,57)}=18.3, \mathrm{P}<0.001\right.$, Fig. 3A $)$ and a lower percentage of eggs hatched in the shortest photoperiod $\left(\mathrm{F}_{(2,57)}=2.8, \mathrm{P}=\right.$ 0.071 , Fig. 3B). Contrasting light vs dark periods on a per6 hour adjusted basis, reveals the extent to which photoperiod affected the partitioning of behaviors between light and dark periods (Table 4). Male pursuit times were consistently longer in daytime than at night, whereas durations of copula were consistently shorter in the day. Under short and intermediate daylengths, more copulations occurred in the daytime, whereas under the longest daylength, more copulations occurred at night.

\section{Wavelength}

Wavelength of light affected both the duration of pursuits and duration of copula, but not the initial latent period prior to copula (Table 5). The fastest pursuits occurred under blue light and the longest under green. Duration of copula was greatest under green and yellow light and was reduced at wavelengths either shorter or longer, whereas number of copulations was highest under green and orange light and lower at all other wavelengths. Both 10-d fecundity $\left(\mathrm{F}_{(5,114)}=250.2, \mathrm{P}<0.001\right)$ and egg fertility $\left(\mathrm{F}_{(5,114)}=18.9\right.$, $\mathrm{P}<0.001)$ varied significantly as a function of wavelength; fecundity peaked under yellow light and fertility peaked under green (Figs 4A and B, respectively).

TABLE 2. Mean ( \pm SE) duration of various components of mating behavior when 10 d-old virgin Propylea japonica adults $(n=20$ per treatment) were paired in an experimental arena for $24 \mathrm{~h}$ under a 12L : 12D photoperiod and one of six different intensities of white light (1500 lux). All replicates were initiated in photophase.

\begin{tabular}{ccccc}
\hline Light intensity (lux) & Latent period (min) & Pursuit time (s) & No. copulations & Duration of copula (min) \\
\hline 600 & $303.8 \pm 9.4 \mathrm{c}$ & $5.3 \pm 0.06 \mathrm{c}$ & $3.2 \pm 0.09 \mathrm{c}$ & $141.7 \pm 2.1 \mathrm{~b}$ \\
900 & $326.7 \pm 3.6 \mathrm{ab}$ & $5.9 \pm 0.05 \mathrm{a}$ & $3.4 \pm 0.11 \mathrm{c}$ & $152.6 \pm 3.9 \mathrm{a}$ \\
1200 & $311.2 \pm 4.1 \mathrm{bc}$ & $5.4 \pm 0.16 \mathrm{c}$ & $4.0 \pm 0.10 \mathrm{~b}$ & $103.9 \pm 4.3 \mathrm{bc}$ \\
1500 & $328.9 \pm 5.0 \mathrm{a}$ & $5.8 \pm 0.08 \mathrm{ab}$ & $4.3 \pm 0.10 \mathrm{~b}$ & $112.7 \pm 3.0 \mathrm{~b}$ \\
1800 & $322.1 \pm 4.6 \mathrm{ab}$ & $5.5 \pm 0.13 \mathrm{bc}$ & $4.3 \pm 0.10 \mathrm{~b}$ & $98.0 \pm 3.1 \mathrm{c}$ \\
2100 & $309.6 \pm 8.6 \mathrm{bc}$ & $5.4 \pm 0.14 \mathrm{c}$ & $5.0 \pm 0.13 \mathrm{a}$ & $80.3 \pm 3.8 \mathrm{~d}$ \\
$\mathrm{~F}$ & 2.64 & 3.93 & 39.5 & 62.9 \\
df & 5,114 & 5,114 & 5,114 & 5,114 \\
$\mathrm{P}$ & 0.027 & 0.003 & $<0.001$ & $<0.001$ \\
\hline
\end{tabular}



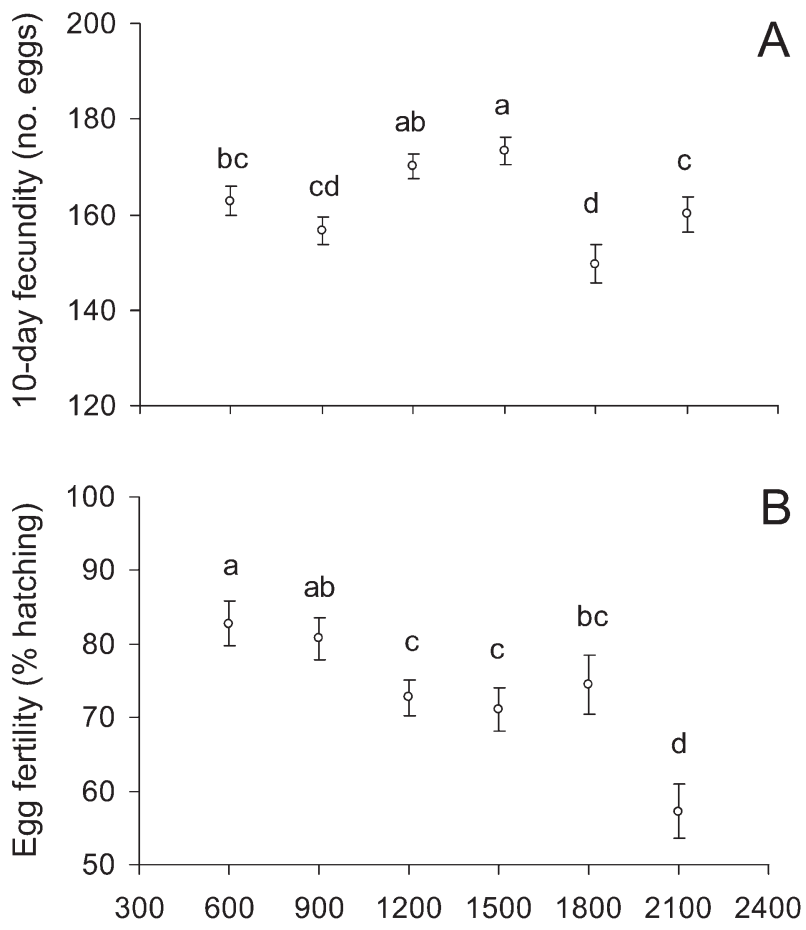

Light intensity (lux)

Fig. 2. Mean ( \pm SE) 10-d fecundities (A) and egg fertilities (B) of Propylea japonica females $(n=20$ per treatment) mated and held under various intensities of white light supplied in a 12L: 12D photoperiod. Values bearing the same letter were not significantly different (Fisher's LSD test, $\alpha=0.05$ ).

\section{DISCUSSION}

Because there exist no discernable differences between male and female $P$. japonica with respect to the ultrastructure of their compound eyes (Yan et al., 2006) it is tempting to assume that the sexes have similar visual abilities. However, inferences from the observed behavioral metrics require some assumptions of gender-specific roles in mating events. For example, female coccinellids use various techniques to defend against male advances, with varying degrees of success. These include kicking at the male, dislodging the male by shaking the abdomen, and employing evasive movements to escape mounting (e.g., Obata, 1988; Wang et al., 2009). Therefore, it is often assumed that females exert the balance of control over initiation of copula,

TABLE 3. Mean $( \pm \mathrm{SE})$ duration of various components of mating behavior when 10 d-old virgin Propylea japonica adults (n $=20$ per treatment) were paired in an experimental arena for 24 $\mathrm{h}$ in three different photoperiods of white light (1500 lux). All replicates were initiated in photophase.

\begin{tabular}{cccc}
\hline $\begin{array}{c}\text { Photoperiod } \\
\text { (L:D) }\end{array}$ & $\begin{array}{c}\text { Pursuit } \\
\text { time (s) }\end{array}$ & $\begin{array}{c}\text { No. } \\
\text { copulations }\end{array}$ & $\begin{array}{c}\text { Duration of } \\
\text { copula (min) }\end{array}$ \\
\hline $6: 18$ & $3.5 \pm 0.13 \mathrm{c}$ & $4.2 \pm 0.08 \mathrm{~b}$ & $143.6 \pm 3.4 \mathrm{a}$ \\
$12: 12$ & $4.3 \pm 0.16 \mathrm{~b}$ & $4.2 \pm 0.08 \mathrm{~b}$ & $96.7 \pm 2.8 \mathrm{~b}$ \\
$18: 6$ & $4.7 \pm 0.07 \mathrm{a}$ & $5.0 \pm 0.05 \mathrm{a}$ & $80.2 \pm 1.9 \mathrm{c}$ \\
$F$ & 22.8 & 40.2 & 141.2 \\
df & 2,57 & 2,57 & 2,57 \\
$P$ & $<0.001$ & $<0.001$ & $<0.001$ \\
\hline
\end{tabular}
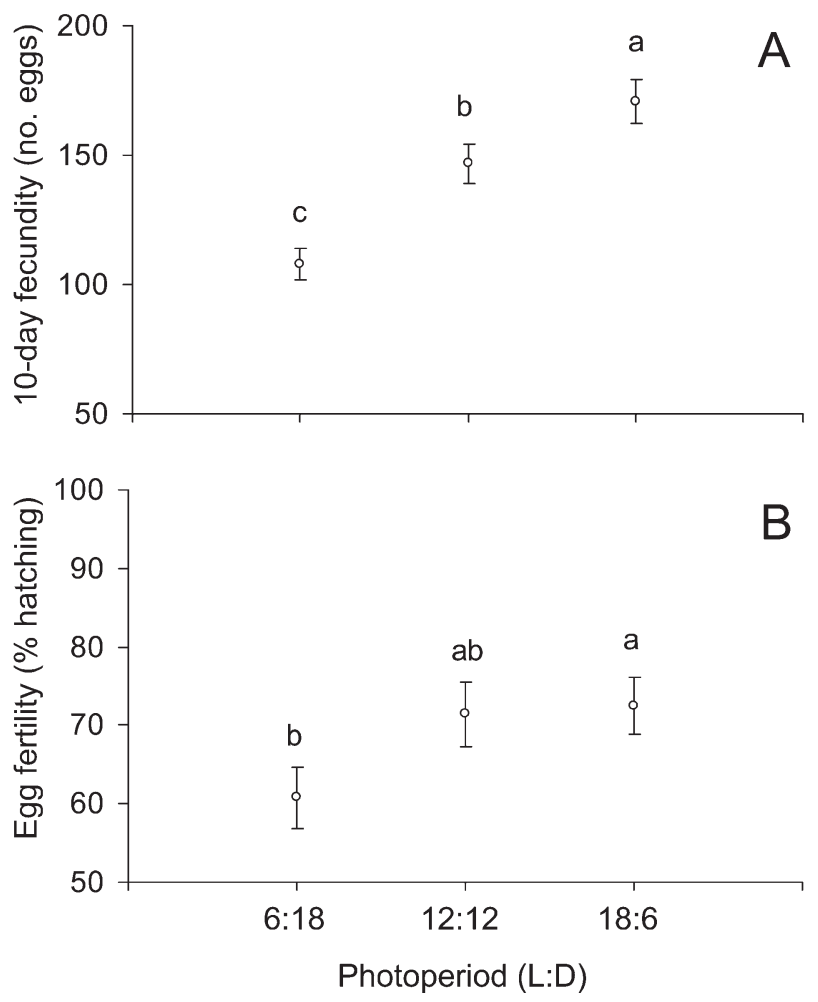

Fig. 3. Mean ( \pm SE) 10-d fecundities (A) and egg fertilities (B) of Propylea japonica females $(n=20$ per treatment) mated and held under various photoperiods of white light provided at 1500 lux. Values bearing the same letter were not significantly different (Fisher's LSD test, $\alpha=0.05$ ).

whereas the male clearly controls its duration (Wang et al., 2009).

TABLE 4. Means ( \pm SE) of various components of mating behavior in light and dark periods when $10 \mathrm{~d}$-old virgin Propylea japonica adults ( $\mathrm{n}=20$ per treatment) were paired in an experimental arena for $24 \mathrm{~h}$ in three different photoperiods of white light (1500 lux). All replicates were initiated in photophase. Data for no. copulations are expressed on a per- $6 \mathrm{~h}$ basis to standardize time frames.

\begin{tabular}{cccc}
\hline Period & Pursuit time (s) & $\begin{array}{c}\text { Duration of } \\
\text { copula (min) }\end{array}$ & No. copulations \\
\hline & \multicolumn{3}{c}{$6 \mathrm{~L}: 18 \mathrm{D}$} \\
Light & $2.5 \pm 0.09$ & $121.8 \pm 7.2$ & $2.6 \pm 0.20$ \\
Dark & $1.0 \pm 0.16$ & $165.4 \pm 1.6$ & $0.5 \pm 0.06$ \\
$F$ & 77.3 & 34.7 & 87.9 \\
df & 1,38 & 1,38 & 1,38 \\
$P$ & $<0.001$ & $<0.001$ & $<0.001$ \\
\cline { 2 - 4 } Light & $2.9 \pm 0.13$ & $72.6 \pm 6.3$ & $1.4 \pm 0.09$ \\
Dark & $1.4 \pm 0.17$ & $120.8 \pm 2.8$ & $0.7 \pm 0.08$ \\
$F$ & 42.5 & 49.2 & 40.5 \\
df & 1,38 & 1,38 & 1,38 \\
$P$ & $<0.001$ & $<0.001$ & $<0.001$ \\
\cline { 2 - 4 } Light & $3.9 \pm 0.10$ & $18 \mathrm{~L}: 6 \mathrm{D}$ & $1.1 \pm 0.06$ \\
nark & $0.8 \pm 0.09$ & $102.2 \pm 1.2$ & $1.6 \pm 0.17$ \\
$F$ & 562.1 & 121.7 & 5.5 \\
df & 1,38 & 1,38 & 1,38 \\
$P$ & $<0.001$ & $<0.001$ & 0.025 \\
\hline \hline
\end{tabular}



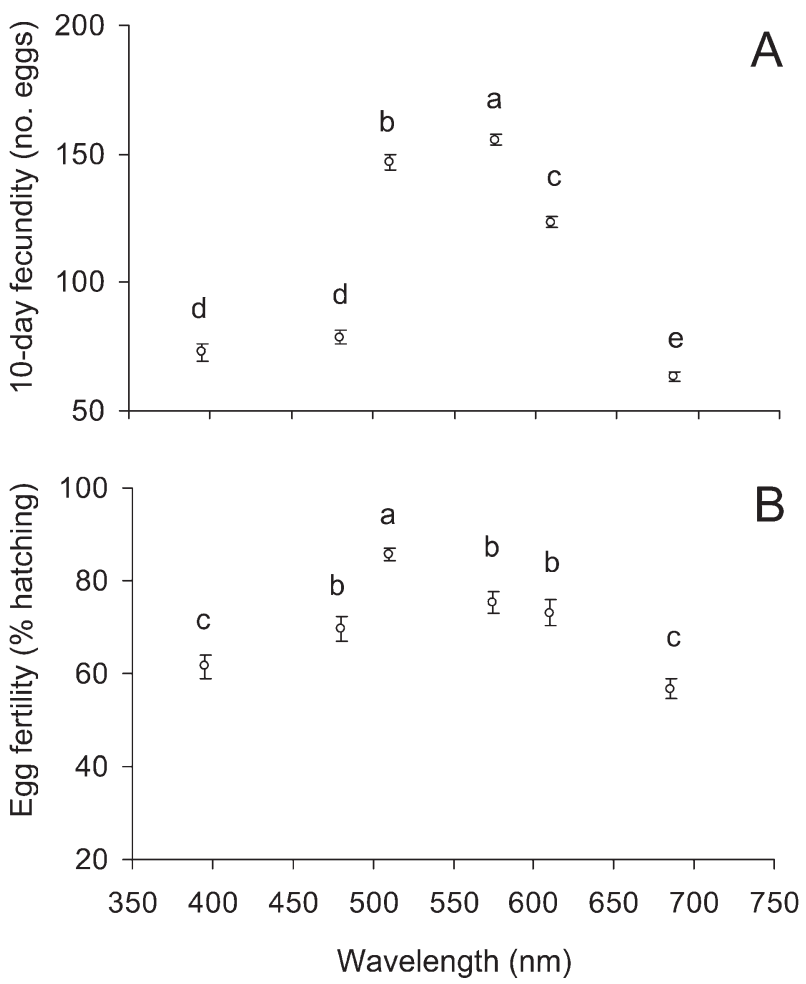

Fig. 4. Mean ( \pm SE) 10-d fecundities (A) and egg fertilities (B) of Propylea japonica females ( $\mathrm{n}=20$ per treatment) mated and held under various wavelengths of light under a $12 \mathrm{~L}: 12 \mathrm{D}$ photoperiod. Values bearing the same letter were not significantly different (Fisher's LSD test, $\alpha=0.05$ ).

If females utilize visual cues to evaluate males during the pursuit phase, they may accept males more quickly in the dark because they are unable to evaluate visual criteria, which could explain the greatly reduced male pursuit times in the dark compared to light in the present experiments. Alternatively, females may simply be more passive in darkness. There was also a reduction in the latent period prior to copula in the dark, suggesting that mutual encounter occurred more quickly in the arena in the absence of light. Possible explanations for this include males being relatively more active than females in the dark, or females visually recognizing male approach under lighted conditions and taking evasive action to extend male searching behavior. Although the frequency of copulations was reduced under dark conditions, the duration of each was increased (except for dark periods under 18:6 daylength conditions). This may simply reflect the fact that female encounters in the dark are infrequent under natural conditions, so males have less incentive to abandon one female and search for another. Alternatively, the risk of predation by birds or other predators may be higher for mating pairs under lighted conditions (Majerus, 1994), which could also favor males abandoning females more quickly.

Light intensity may be one factor influencing microhabitat selection by insects and different light intensities may be optimal for different behaviors and biological functions. In nature, strong light intensities will be associated with higher temperatures and perhaps with higher risk of predation. This may partly explain why the number of daily copulations increased with light intensity, while their average duration decreased. The effects on the latent period to copula and male pursuit times are difficult to interpret, but in both cases dim and bright light tended to result in the fastest onset of copula, possibly due to entirely different effects, whereas slower coupling occurred under intermediate light intensities. Effects on reproductive success were less ambiguous; increasing light intensity stimulated female egg production up to 1500 lux, whereas egg fertility was maximal at the lowest intensity. As the earliest developmental stage, eggs are likely more sensitive to radiation damage than later stages, which would explain why females typically lay egg clusters in shade on the abaxial surfaces of leaves.

The responses of $P$. japonica to different photoperiods are indicative of an insect adapted to maximal reproductive activity under long day conditions, consistent with its seasonal peak of field activity in China which typically occurs mid-summer to early fall (Liu \& He, 2009). Both fecundity and egg fertility were maximized by the longest daylength, and these conditions also generated the highest number of copulations, although they were the shortest in duration. Thus, the low egg fertility observed at high light intensities are not likely the result of shorter copulation times resulting in reduced sperm transfer. In similar work, Zilahi-Balogh et al. (2006) found that two whitefly parasitoids foraged most effectively under relatively high light intensity and long day conditions. More prolonged exposure to short daylength would likely induce diapause, as it does in many temperate climate species (Voronin, 1965;

TABLE 5. Means $( \pm \mathrm{SE})$ of various components of mating behavior when $10 \mathrm{~d}$-old virgin Propylea japonica adults $(\mathrm{n}=20$ per treatment) were paired in an experimental arena for $24 \mathrm{~h}$ under a 12L : 12D photoperiod and one of six different wavelengths of light at 1500 lux. All replicates were initiated in photophase.

\begin{tabular}{ccccc}
\hline Wavelength $(\mathrm{nm})$ & Latent period $(\mathrm{min})$ & Pursuit time $(\mathrm{s})$ & No. copulations & Duration of copula (min) \\
\hline 395 (violet) & $411.7 \pm 13.3 \mathrm{a}$ & $3.3 \pm 0.7 \mathrm{bc}$ & $3.9 \pm 0.07 \mathrm{c}$ & $124.1 \pm 8.8 \mathrm{~b}$ \\
48 (blue) & $403.2 \pm 19.8 \mathrm{a}$ & $3.1 \pm 0.7 \mathrm{c}$ & $3.5 \pm 0.11 \mathrm{~d}$ & $127.6 \pm 12.3 \mathrm{~b}$ \\
510 (green) & $395.7 \pm 11.2 \mathrm{a}$ & $3.6 \pm 0.6 \mathrm{a}$ & $5.4 \pm 0.11 \mathrm{a}$ & $163.7 \pm 10.5 \mathrm{a}$ \\
575 (yellow) & $413.6 \pm 13.4 \mathrm{a}$ & $3.4 \pm 0.5 \mathrm{ab}$ & $5.1 \pm 0.05 \mathrm{~b}$ & $160.5 \pm 10.6 \mathrm{a}$ \\
610 (orange) & $404.7 \pm 16.9 \mathrm{a}$ & $3.2 \pm 0.7 \mathrm{bc}$ & $5.6 \pm 0.13 \mathrm{a}$ & $103.2 \pm 9.8 \mathrm{c}$ \\
685 (red) & $392.8 \pm 15.7 \mathrm{a}$ & $3.2 \pm 0.3 \mathrm{bc}$ & $5.5 \pm 0.11 \mathrm{a}$ & $76.4 \pm 11.3 \mathrm{~d}$ \\
$F$ & 1.03 & 2.82 & 74.5 & 52.3 \\
df & 5,114 & 5,114 & 5,114 & 5,114 \\
$P$ & 0.404 & 0.947 & $<0.001$ & $<0.001$ \\
\hline
\end{tabular}


Denlinger, 2002). However, short of diapause induction, daylength has been shown to influence reproductive performance in many insects (e.g., Omkar et al., 2013; Tu et al., 2013; Wang et al., 2013a,b), although Bahsi \& Tunc (2008) found few significant effects on the development and reproduction of Orius niger Wolff. Typically, longer daylengths are most favorable for coccinellid reproduction (Mishra \& Omkar, 2005; Wang et al., 2013b). Similarly, McMurtry et al. (1974) reported that oviposition in the mite predator Stethorus picipes Casey was inhibited by short daylength and maximal at 16L : 8D.

Coccinellid species are known to vary in their behavioral responses to short wavelengths of light (Nalepa, 2013) and previous studies have revealed negative effects of red light on the development and reproduction of ladybirds (Omkar et al., 2005). Green light was generally the most beneficial wavelength for $P$. japonica reproduction, with yellow a close second. The $510 \mathrm{~nm}$ wavelength generated the highest number of copulations and those of longest duration. Although a slightly higher fecundity was obtained under yellow light, green light yielded substantially higher egg fertility such that a mean of 126 viable offspring were produced in ten days, compared to 117 under yellow. This result might be expected because all life stages of aphidophagous coccinellids occur on plants and spend most of their time within plant canopies where green is the dominant color reflected. Once again, reduced sperm transfer is not a likely explanation of the low egg fertility under long and short wavelengths due to its inverse relationship with egg fertility in the daylength experiment. Thus we are inclined to attribute treatment effects on fecundity mostly to maternal responses to lighting environments, and effects on fertility mostly to differential sensitivity of the eggs. This inference of egg sensitivity to light is supported by the results of the first experiment where a higher hatching rate was obtained in full darkness than in full light, even though female fecundity did not differ.

In conclusion, all light conditions tested had significant effects on $P$. japonica reproductive performance. Consequently, the present findings can be used to infer the ideal photic conditions for $P$. japonica reproduction in massreared colonies. To maximize reproductive success, beetles should be housed in cages under an overhead light source generating 1500 lux of white light in a $18 \mathrm{~L}$ : 6D photoperiod. Although $P$. japonica can be conveniently reared on encapsulated artificial diet (Tan et al., 2014), this denies the insects plant material and thus any beneficial effects of exposure to reflected green light. We hypothesize that improved reproductive performance might be obtained with reusable artificial leaves, cut from thin sheets of green plastic film clipped to vertical supports in a horizontal orientation to serve as oviposition substrates. These would be easily replaced on a daily basis, facilitating egg harvest, and would expose adults to reflected green light, as occurs in a natural plant canopy, while simultaneously providing shade for the egg clusters laid on the lower surfaces, reducing the intensity of light impinging upon them. Once harvested, the eggs could be transfered to complete darkness to further improve their hatching rate, which was maximal under dark conditions in these experiments. Additional research is required to determine the optimal photic conditions for larval development, but these could also be taylored for optimal developmental outcomes, as larvae are already held separately from ovipositing adults to prevent egg cannibalism.

ACKNOWLEDGEMENTS. This study was funded through the Major State Basic Research Development Program of China (973 Program, No. 2013CB127605) and the Special Fund for Agroscientific Research in the Public Interest (No. 201303108). We are grateful to D.-X. He of China Agricultural University for advice on lighting.

\section{REFERENCES}

Abenes M. \& Khan Z. 1990: Attractiveness of light color to selected predators of rice pests. - Int. Rice Res. News 15: 24-25.

BAHSI S. \& TUNC I. 2008: Development, survival and reproduction of Orius niger (Hemiptera: Anthocoridae) under different photoperiod and temperature regimes. - Biocontr. Sci. Tech. 18: 767-778.

BecK S. 1974: Photoperiodic determination of insect development and diapause. - J. Compar. Physiol. 90: 275-295.

Chi H. \& Yang T. 2003: Two-sex life table and predation rate of Propylaea japonica Thunberg (Coleoptera: Coccinellidae) fed on Myzus persicae (Sulzer) (Homoptera: Aphididae). — Environ. Entomol. 32: 327-333.

Denlinger D.L. 2002: Regulation of diapause. Annu. Rev. Entomol. 47: 93-122.

Goff A. \& NaUlt L. 1984: Response of the pea aphid parasite Aphidius ervi Haliday (Hymenoptera: Aphidiidae) to transmitted light. — Environ. Entomol. 13: 595-598.

HARMON JP., Losey J.E. \& Ives A.R. 1998: The role of vision and color in the close proximity foraging behavior of four coccinellid species. - Oecologia 115: 287-292.

KaWAUCHI S. 1983: The threshold temperature and thermal constant for development from the egg to the adult form of Coccinella septempunctata brucki, Propylea japonica and Scymnus (Pullus) hoffmanni (Coleoptera, Coccinellidae). - Kurume Univ. J. 32: 45-51.

Kennedy J.S., Booth C.O. \& Kershaw W.J.S. 1961: Host fnding by aphids in the field. - Ann. Appl. Biol. 49: 1-21.

Langevelde F. van, Ettema J.A., Donners M., WallisDeVries M.F. \& GRoendiJK D. 2011: Effect of spectral composition of artificial light on the attraction of moths. - Biol. Conserv. 144: 2274-2281.

Liu J.H. \& HE D.H. 2009: The community composition and niche of ladybirds in orchard of American apricot and plum. - Chinese Bull. Entomol. 46: 445-449.

Majerus M.E.N. 1994: Ladybirds. Harper Collins, London, 367 pp.

Malaquias J., Ramalho F., Fernandes F., Junior J., Correia E. \& ZANUNCIO J. 2010: Effects of photoperiod on reproduction and longevity of Podisus nigrispinus (Heteroptera: Pentatomidae). - Ann. Entomol. Soc. Am. 103: 603-610.

McMurtry J.A., Scriven G.T. \& Malone R.S. 1974: Factors affecting oviposition of Stethorus picipes (Coleoptera: Coccinellidae), with special reference to photoperiod. - Environ. Entomol. 3: 123-127.

Mishra G. \& OMKar 2005: Influence of light components on the life attributes of an aphidophabous ladybird, Propylea dissecta (Coleoptera: Coccinellidae). - Int. J. Trop. Insect Sci. 25: 32-38. 
NAKAMUTA K. 1984: Visual orientation of a ladybeetle, Coccinella septempunctata L. (Coleoptera: Coccinellidae) towards its prey. - Appl. Entomol. Zool. 19: 82-86.

NALEPA C.A. 2013: Coccinellidae captured in blacklight traps: seasonal and diel pattern of the dominant species Harmonia axyridis (Coleoptera: Coccinellidae). — Eur. J. Entomol. 110: 593-597.

Noldus N., Spink A. \& Tegelenbosch R. 2002: Computerised video tracking, movement analysis and behaviour recognition in insects. - Comp. Electron. Agric. 35: 201-227.

Овата S. 1988: Mating refusal and its significance in females of the ladybird beetle, Harmonia axyridis. - Physiol. Entomol. 13: $193-199$

OMKar, Mishra G. \& Singh K. 2005: Effects of different wavelengths of light on the life attributes of two aphidophagous ladybirds (Coleoptera: Coccinellidae). — Eur. J. Entomol. 102: 33-37.

Omkar, Rastogi S. \& Pervez A. 2013: Demographic attributes of the parthenium beetle Zygogramma bicolorata (Coleoptera: Chrysomelidae) under different variables. - Int. J. Trop. Insect Sci. 33: 170-177.

OMKaR \& PATHAK S. 2006: Effects of different photoperiods and wavelengths of light on the life-history traits of an aphidophagous ladybird, Coelophora saucia (Mulsant). - J. Appl. Entomol. 130: 45-50.

OuYang F., Men X.Y., Yang B., Su J.W., Zhang Y.S., Zhao Z.H. \& Ge F. 2012: Maize benefits the predatory beetle, Propylea japonica (Thunberg), to provide potential to enhance biological control for aphids in cotton. PloS One 7: e44379.

Pan Y., Hu Y.W., Zhou X.M., Fang L. \& Lei C.L. 2010: Biological characteristics and environmental adaptation of four phenotypes of Propylea japonica (Thunberg) (Coleoptera: Coccinellidae). - Coleopt. Bull. 64: 249-255.

Pawson S., Watt M. \& Brockerhoff E. 2009: Using differential responses to light spectra as a monitoring and control tool for Arhopalus ferus (Coleoptera: Cerambycidae) and other exotic wood-boring pests. - J. Econ. Entomol. 102: 79-85.

Perdikis D.C., Lykouressis D.P. \& Economu L.P. 2004: Influence of light-dark phase, host plant, temperature, and their interactions on the predation rate in an insect predator. - Environ. Entomol. 33: 1137-1144.

Rasekh A., Michaud J.P., Allahyari H. \& Sabahi Q. 2010: The foraging behavior of Lysiphlebus fabarum (Marshall), a thely- tokous parasitoid of the black bean aphid in Iran. - J. Insect Behav. 23: 165-179.

Tan X., Zhao J., Wang S. \& Zhang F. 2014: Optimization and evaluation of microencapsulated artificial diet for mass rearing the predatory ladybird Propylea japonica (Coleoptera: Coccinellidae). - Insect Sci. [in press].

Tu X.Y., Zeng L.Q., Dong X.H., Li S.N., Yang Y.P. \& Xu F. 2013: Effects of photoperiod on the mating and oviposition of Brithys crini. - Chinese J. Appl. Entomol. 50: 1238-1243.

VeERESH G.K. 1974: Attraction of Coccinellid predator Coccinella repanda Thunb. var. transversalis Fabr. (Coccinellidae, Coleoptera) to black light. — Curr. Res. 3: 101-102.

Voronin K.E. 1965: Features of the formation of the overwintering population of Harmonia (Harmonia axyridis Pallas) - a predator of aphids in the Far East. — Trudy Vses. Inst. Zashch. Rast. 24: 228-233.

Wang S., Michaud J.P., Zhang R., Zhang F. \& Liu S. 2009: Seasonal cycles of assortative mating and reproductive behaviour in polymorphic populations of Harmonia axyridis in China. Ecol. Entomol. 34: 483-494.

Wang S., TAn X., Michaud J.P. \& Zhang F. 2013a: Light intensity and wavelength influence development, reproduction and locomotor activity in the predatory flower bug Orius sauteri (Poppius) (Hemiptera: Anthocoridae). — BioControl 58: 667-674.

Wang S., TAN X., Guo X. \& Zhang F. 2013b: Effect of temperature and photoperiod on the development, reproduction, and predation of the predatory ladybird Cheilomenes sexmaculata (Coleoptera: Coccinellidae). - J. Econ. Entomol. 106: 26212629.

WANG X.X., OuYAng F. \& LiU Y.F. 2013c: Effects of farmland landscape patterns on the population dynamics of two lady beetles. - Chinese J. Appl. Entomol. 50: 903-911.

Yan H.Y., Wei G.S., Yan H.X. \& Feng L. 2006: The morphology and fine structure of the compound eye of Propylea japonica. - Chinese Bull. Entomol. 43: 344-348.

Zhang S., Zhang F. \& Hua B. 2007: Suitability of various prey types for the development of Propylea japonica (Coleoptera: Coccinellidae). — Eur. J. Entomol. 104: 149-152.

Zilahi-Balogh G., Shipp J., Cloutier C. \& Brodeur J. 2006: Influence of light intensity, photoperiod, and temperature on the efficacy of two aphelinid parasitoids of the greenhouse whitefly. - Environ. Entomol. 35: 581-589.

Received March 17, 2014; revised and accepted April 28, 2014 Prepublished online May 27, 2014 